\title{
COMPETITIVE CAPABILITY-BUILDING FOR INTEGRATED DESIGN SCHEDULING AND MANAGEMENT
}

\author{
Dean Reed ${ }^{1}$, Will Powell ${ }^{2}$, and Peter Berg ${ }^{3}$
}

\begin{abstract}
This paper explores the relevance of Takahiro Fujimoto's theory of the role capabilitybuilding played in the emergence of the Toyota Production System to design and construction. It is the third in a series on this topic. The research question is whether Fujimoto's explanation of how capability was built within Toyota can help project teams build better capability leading to system-level improvement. In this new paper the authors connect Fujimoto's evolutionary perspective with the possibility that complex systems theory is a useful starting point for understanding design and construction. The authors explain Fujimoto's theory and how they used it to evaluate building-capability for Integrated Design Scheduling and Management on several projects they reviewed retrospectively. Key findings are: 1, effective use of routines is important and a prerequisite for effectiveness; 2, routinized capability (regular patterns of doing essential things) is essential to affect change at system level; 3 , entrepreneurial leadership is necessary for effective capability-building, and 4, system emergence, where there is no relationship between the content and pattern of system changes, together with routinized capability is possible although rare; 5 ; this is also possible, but even more rare with a second, systems level of problem solving.
\end{abstract}

\section{KEYWORDS}

Theory, capability, complexity, emergence, evolutionary.

\section{INTRODUCTION}

A survey of IGLC papers indicates a gap in literature using Takahiro Fujimoto's theory of emergent development of the Toyota Production System to understand building of competitive capability-building. A search of all previous papers on the IGLC.net website with these keywords: capability, capability-building, emergence, evolutionary, Fujimoto and Pucchi found 5 papers referencing Fujimoto. Two were authored by the first and third authors of this paper, two by Flávio Picchi, and one by others. Only the authors' previous 2 papers

1 Owner and Consultant, Capability-Building, Santa Cruz, CA 95060, USA, +1 6502073486 , dean@deansreed.com, orcid.org/0000-0002-2916-8558

2 Integrated Design Scheduling and Management Subject Matter Expert, DPR Construction, San Diego, CA 92122, USA, +1 858597 7070, willpo@dpr.com, orcid.org/0000-0003-4720-4572

3 Project Executive, DPR Construction, Phoenix, AZ 85034, USA, +1 602808 0500, peterb@dpr.com, orcid.org/0000-0002-8227-2012 
used Fujimoto's theory to examine design and construction operations capability-building. The first paper focused on developing capability on 6 different projects to prefabricate exterior wall panels on construction sites and install them (Berg and Reed 2019). The second used Fujimoto's theory to explain capability-building for "Programmatic Spatial Cost Modeling" on a series of 7 building projects (Berg et al 2020). This paper is a retrospective study to understand how competitive capability for Integrated Design Scheduling and Management (IDSM) has been built and extended within projects. As with the 2 previous papers, the limitation of this paper is that it relies on assessments by a single subject matter expert (SME) because none of the capability-building was designed and carried-out with Fujimoto's theory in mind. In this case the research assessments were made retrospectively by the second author, who was the capability SME.

Fujimoto explains the development and functioning of the Toyota Production System (TPS) from an evolutionary perspective (Takahiro Fujimoto 1999), which he does not associate with complex systems theory. The authors do connect the two perspectives. This is because complexity theory sees human actions and behaviors as a response to intersections of factors in dynamic complex systems which are so specific to local conditions that they can never be completely designed or described entirely by humans or even computers. The evolutionary and complex system perspectives are synergistic because they both look up and across organizations rather than down and into them to explain the why and how of innovations and accidents, successes, and failures in project delivery. Neither focuses on the behaviors of exceptional leadership nor the dedication and discipline of individual performers. Systems thinkers argue that behavior and outcomes emerge from local intersections of interests and actions by well-intended people.

The authors agree with Bertelsen that a systems approach will enable better performance outcomes for lean thinkers in the Construction industry (Bertelsen 2003). Sidney Dekker and others who've studied adaptive complex systems offer an alternative to the dominant deterministic worldview that causes can be identified to explain breakdowns. The authors suspect that constructors will appreciate Dekker, a leading safety researcher and thinker, because he uses complex systems theory to explain why well intended efforts focused on controlling behaviors fail to prevent serious accidents, which continue to occur all too often in the Construction industry (Dekker 2011)

\section{THE PROBLEM AND A METHOD TO SOLVE IT}

Toyota and every other automaker develop the products they make. This is often not the case for construction projects. Regardless of whether this work is done inside or outside of building companies, design work must be done well within an allotted time. Safe, high quality and efficient construction depends on the quality and timeliness of the design work product. In the authors' experience, designs are either often completed during construction, and / or the process of design is not adequately aligned with construction and procurement deadlines, leading to knock-on effect delays and the potential for costly rework. That's why the capability to design buildings that meet customer needs and expectations in a way that supports procurement, fabrication and final assembly is a competitive advantage.

Design Structure Matrix (DSM) is an analysis model for identifying information dependency, which Tuholski and Tommelein explained well in a previous IGLC paper (Tuholski and Tommelein 2008). Founders of Adept Management Limited (AML), 
participated as industry practitioners in research on its application to AEC in the 1990s, and began consulting with teams to use DSM on large, complex projects in 2001. They applied the Analytical Design Planning Technique (ADePT), which they had helped invent (Austin et al. 2002).

The second author, the expert who worked with every one of the teams on all the projects studied here, spent 18 years as a deployment specialist for AML helping project teams implement a highly structured, repeatable process in which progress towards well defined deliverables could be measured. AML's practice was to bring their SMEs together regularly to report on and discuss their work. He joined a large U.S. based General Contractor (GC) in 2020. In all, he taught the ADePT method and use of the routines identified in this paper to teams on over 40 projects. He selected 11 diverse projects for this study, the earliest beginning in 2010 and the latest ongoing, representing a range of responses to the challenge of scheduling and managing design in an integrated way for this study.

\section{THE THEORY OF CAPABILITY-BUILDING COMPETITION}

\section{Evolutionary Perspective}

The Toyota Production System (TPS) is a complex web of capabilities invented and refined to solve specific problems throughout this particular automaker. There was no grand design; TPS evolved over time (Shimokawa and Takahiro Fujimoto 2009). Its logic can only be seen in hindsight looking backward. Ways of functioning and the outcomes they produce, or influence emerge in complex systems that are dynamic by nature. Fujimoto argues that this provides the best framework for explaining Toyota and other Japanese automakers he studied (Fujimoto 1999).

Fujimoto defines organizational capability as the power or ability of an organized group to do something using effective routines. The word "routine" derives from the French word for path and encompasses the concept of patterns. Charles Duhigg explains how capability is built and exercised by people creating and following routines (Duhigg 2012). Capability can be exceptional and episodic or consistent and a matter of course.

Fujimoto closely links capability with problem-solving. Solutions must be made real and tangible, i.e., converted, through capabilities. What he calls "Dual-Layer Problem-Solving" is a capability to combine solutions to solve seemingly unrelated or new problems. This requires leaders with authority to be intentional in doing this work.

\section{INFORMATION AND MANUFACTURING CAPABILITY}

Fujimoto believes that the capability to make things depends on capabilities to create, transform, and transfer information to make products. Toyota has focused on capabilities to make information, material and components flow exactly when they are needed (just-in-time). He argues that the problem-solving cycle of goal setting and problem recognition, searching for feasible alternatives, evaluating alternatives, and selection used in product development is a rich source of information and knowledge. Fujimoto believes that information for making the product connects the routines for product development, suppliers, and fabrication and assembly with the next and ultimate customer. He argues that the flow of information is actually the only way to understand TPS. 
Rather than speeding-up individual operations, Toyota follows a dense information strategy in which only the right information is transmitted repeatedly until received at the right time by the right production resources (people and machines). Fujimoto explains that the imperative for eliminating the 7 wastes identified by Taiichi Ohno (Ohno 1988) is that they prevent these resources from receiving the information they need.

\section{Multiple Paths for DeVeloping Solutions}

Takahiro Fujimoto identifies 5 paths for generating solutions to problems. Organizational, as opposed to individual, capabilities are a sequence of steps a group routinely follow in a specific way to solve a problem or implement a solution. These are the 5 paths:

1 Rational Calculation. For Fujimoto this is the complete problem-solving cycle for product development of goal setting and problem recognition, searching for feasible alternatives, evaluating alternatives and selection. Previously, the authors misinterpreted this as careful planning.

2 Environmental Constraints. This is finding and deciding between feasible alternatives constrained by external factors.

3 Entrepreneurial Vision. This is pursuing solutions advocated by leaders. While these leaders are often in positions of formal authority, they need not be.

4 Knowledge Transfer. This means following the advice of experts from outside the project. Often these experts are professional trainers and coaches.

5 Random Trails. This is trying different solutions advocated by leaders.

These paths are not mutually exclusive; one or more can influence problem-solving work.

\section{Three LeVels of Manufacturing Capability}

As noted in This Is Lean (Modig and Åhlström 2012) and by Flávio Pucchi (2001), Fujimoto identifies 3 levels of manufacturing, as follows.

- Routinized Production Capability. The basic nature of routinized production capability is static and regular; variability is low. Its influence is competitive performance in a stable environment where necessary prerequisites flow and the product can be made predictably. Its primary characteristics are a firm or projectspecific pattern of steady-state and efficient transfer of accurate information.

- Routinized Learning Capability. The basic nature of routinized learning is dynamic and routine so that people have regular ways for dealing with variability. Its influence is changes or recoveries of competitive performance in a dynamic environment. Its primary characteristics are a firm or project-specific ability of handling repetitive problem-solving cycles or an expected pattern of system changes.

- Evolutionary Learning Capability. The basic nature of evolutionary learning is dynamic and not regular. Its influence is changes in patterns of routines that contribute to capability. Its primary characteristic is a firm or project-specific ability of handling system emergence, i.e., dealing with non-routine patterns of system changes to form new routine capabilities (Takahiro Fujimoto 1999). 


\section{Multi-Path System Emergence}

Fujimoto asserts that 2 conditions must be present for the 5 paths for developing solutions to influence changes in systems, which he calls "Multi-Path System Emergence."

- There are a variety of patterns in changes to the larger system, in this case project design and engineering. This is indicated by consistent changes in the arrangement and timing of the functioning of the system.

- There is no relation between the pattern of changes and content, meaning the changes aren't limited to certain ways of working or work products in the larger system.

\section{EVOLUTIONARY LEARNING CAPABILITY}

Fujimoto defines a third condition, which is firm specific patterns of routine capabilities for production and learning. This is when capabilities become consistent, i.e., people are regularly following the routines. This combined with Multi-Path System Emergence indicate evolutionary learning capability. This is the capability to build new capability, which Fujimoto points to as the key to Toyota's success.

\section{Dual-Layer / Level Problem Solving}

Fujimoto argues that a two-level capability for problem-solving emerged within Toyota and that this enabled leaders to continually improve competitiveness throughout the organization. $\mathrm{He}$ attributes this to 3 factors, which are preconditions, lower-level paths for solution generation, and higher-level conversion of solutions to competitive capabilities. Preconditions are historical imperatives, visions and strategies and evolutionary capabilities. Lower-level paths are the 5 leading to solutions and system changes. The higher-level is problem-solving for competitive capabilities, which is the essence of deep competition in the auto industry. This involves problem recognition, modification of solutions for competitiveness and selection of partial solutions for the problem. Fujimoto asserts that this leads to retention of solutions and renewed capabilities (Takahiro Fujimoto 1999). Intentional selection and modification of capabilities to produce new ones to solve other problems indicates dual-layer problem-solving for projects with multi-path system emergence and evolutionary learning capability.

\section{CASE STUDY ANALYSIS}

\section{Data Collection \& Evaluation}

All data was provided by the second author, who served as the subject matter expert (SME)

\section{Competitiveness}

First, the expert identified 4 criteria for competitive success, each worth $25 \%$, were as follows:

- No unplanned negative iteration in the design process

- All team members are working on same thing at the same time / coordination amongst the disciplines

- Delivering design packages reliably: on time and meeting agreed quality criteria 
- Team participation: everyone together and on the same page; and committed to follow the process for design scheduling and management

Second, the expert chose 11 projects with diverse scopes to study, as follows:

- New Commercial

- New Hotel / Residential

- New Higher Education Research Lab

- New Corporate Campus

- New Higher Education Research \& Simulation Labs / Conference Center / Classrooms

- New Airport Terminal

- New Hotel \& Entertainment

- New K-12 School

- New Airport Inter-Terminal Transportation

- New Hospital

- New Biotechnology Research Lab

Third, the expert described the routines required for competitive organizational capability, listed in Table 1. Fourth, the expert scored the effective use of each routine for every project using a 0 to 5 scale. It is important to note that while many of the routines are specific to the construction of an integrated design schedule, several go beyond into the ongoing management and leadership required in a continually evolving process. Fifth, the expert rated the capability's contribution to success for each criteria using a 0 to 5 scale.

\section{Multi-Path Development and System Emergence}

Next, the expert answered true / false for whether each of the 5 solution paths contributed to the capability as a whole for each project, which was totaled. The next question was also true / false for whether the expert noticed changes within the larger design and engineering system. If false, meaning no changes, there was no possibility and need to investigate multi-path system emergence, evolutionary learning, and dual-layer problem-solving. That was the case with 8 out of the 11 projects. The next questions were also true / false. The first question was whether the expert saw a variety of patterns (sequence and arrangement) in system changes. The second question was whether the expert saw a clear relationship between the pattern and content of system changes. Multi-path system emergence occurred on only 2 projects precisely because there was no discernible relationship between the pattern and content of system changes, meaning they weren't anticipated or planned. Because both of these projects had routinized capability for design scheduling and management along with multi-path system emergence, they also manifested evolutionary learning capability.

\section{Dual-Layer Problem-Solving}

The last question for the expert, true / false, was whether there was intentional selection and modification of capability solutions to create new capability to solve other problems on the 2 projects that displayed evolutionary learning capability. Only one exhibited this. 


\section{FINDINGS}

Table 1 shows the data that supports the findings listed below it.

Table 1: Competitiveness, Multi-Path System Emergence \& Evolutionary Learning

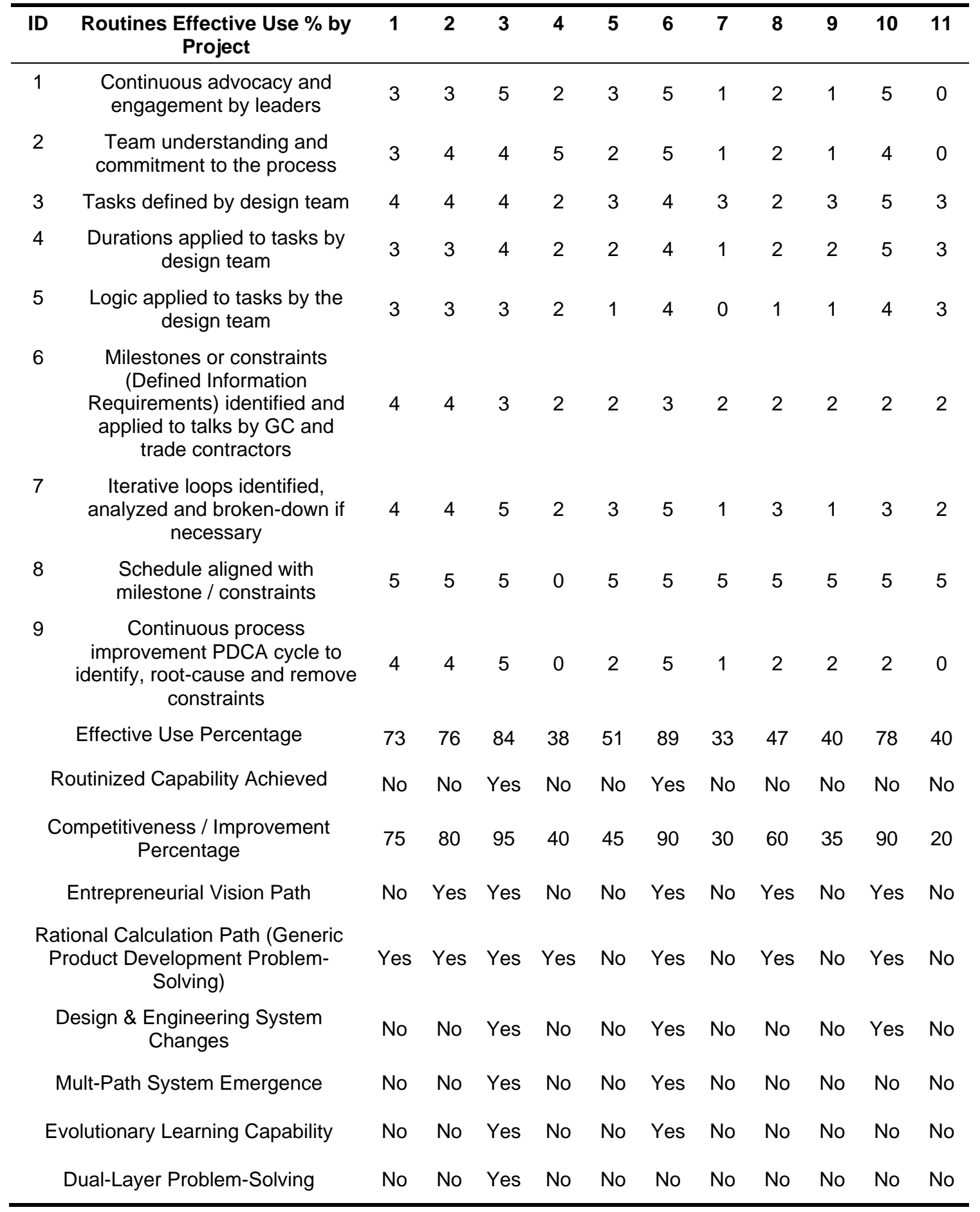


- Effective Use of Routines. The 5 projects with the highest percentage of effective use routines achieved the greatest improvement in competitiveness.

- Routinized Capability. Only 2 of the 11 projects met or exceeded $80 \%$ effective use for the 9 routines, achieving routinized capability.

- Multi-Path Development: Knowledge Transfer contributed to capability on all projects. The 5 projects with no Rational Calculation had the lowest effective use scores, and the 5 with Entrepreneurial Vision had the highest effective use scores.

- Key Routines for Success / Competitiveness. These 2 projects had the highest scores for both of the first 2 routines (Driving Leadership and Team Buy-in to the Process).

- Competitiveness. These 2 projects were also the ones that had over $80 \%$ improvement in competitiveness measured against the 4 success criteria.

- Percentage of Routines Used. The 5 projects having the highest percentage of routines effectively used achieved the highest competitiveness. They also scored higher for effective use of the first 2 routines.

- System Changes. The Integrated Design Scheduling and Management capability in the 2 projects with routinized capability and another that came close led to changes in the larger design and engineering system.

- Multi-Path System Emergence. Only 2 of the projects with system changes did not show a clear relationship between the pattern and content of system change, which characterizes multi-path system emergence.

- Evolutionary Learning Capability. Because Integrated Design Scheduling and Management was routinized, it could be said that these 2 project team displayed evolutionary learning capability.

- Dual-Layer Problem-Solving. This was not visible to the SME on either of the 2 projects which reached that level. However, the third author, who was responsible for outcomes and provided entrepreneurial vision for project 3, did see this and, in fact, consciously leveraged Integrated Design Scheduling and Management capability to create new capabilities. This may also have occurred on the other project. By the time the construction documents are completed, the SME is working with the team remotely and has little or no visibility into how the team has leveraged their new capability. In this study the SME could only report that he could not see dual-layer problem-solving. This question should be put to top-level project leaders. Unfortunately, those people were not available for the other qualifying project.

\section{CONCLUSION}

\section{NEW INSIGHTS}

The authors now believe that stopping to identify constituent routines is necessary for understanding capability, regardless of whether it's individual or organizational. Fujimoto is right in directing attention there. Getting people to agree to work in a sequence of steps in a regular manner and actually doing that are two different things. So, asking an expert in the particular capability whether agreement has led to effective action is essential. Knowing what 
success means is also essential. That begs the question of how often people are carrying out tasks without a clear idea of what the outcome should be. These are just the beginning of understanding how to create organizational capability that improves system performance relative to competitors.

Investigating system emergence using Fujimoto's framework provides the opportunity for much deeper understanding of how people do their work and create capability. Without it, the authors would have focused on tasks executed and behaviors manifested, and attributed success or failure to how individual attitudes and abilities influenced their willingness to learn and implement something new. Nor would the authors have thought about competitive success, nor paid much attention to routines, much less their effective use. It's also likely that there would have been no insights into why or how some project teams succeeded in scheduling and managing design while others did not.

\section{INTUITIONS AND QUESTIONS}

Entrepreneurial Vision (EV) is as important for Integrated Design Scheduling and Management, as it proved to be for Programmatic Spatial Cost Modeling (Berg et al 2020). While the importance of leadership is widely recognized in the Construction industry, it's not generally associated with building capability, which is seen as a matter of training. This begs the question of how it can be included in projects. Bill Seed has described a new integrated project leader that, in our opinion, could drive the development of capabilities (Seed 2014).

Toyota created a new position, the Chief Engineer (Sobek et al. 1998), to drive problemsolving in product development. It seems that a such a person with visibility across so much of this work could promote evolutionary learning and the intentional development of new capabilities during the design of construction projects. Is this required in lieu of or in addition to Seed's new integrated project leader?

Integrated Project Delivery agreements specify the formation of a Project Management Team (PMT) to steer project management (Allison et al. 2018). Ideally, this small team of leaders would include people who individually or in aggregate can assume the responsibilities Seed described. Should this team include or function as the Chief Engineer? Or should they be capable as individuals of leading capability-building to the level of evolutionary learning and dual-layer problem-solving?

\section{FURTHER STUDIES}

The authors' hope for the opportunity to do action research where project leaders and the team or people tasked with executing one or more capabilities can design their work based on the insights gained from this and the two previous studies. The aim would be for those doing this work to evaluate competitiveness and impact on whatever the larger system is during execution. This research will be necessary to understand the limits of competitive capability building for: temporary project organizations versus ones like Toyota organized for continuous production; separate and often fragmented design and construction versus integrated product development; long-term investment timeframes versus short-term; continuous improvement versus quick fixes organizational culture; and stable vs highly variable production. 


\section{REFERENCES}

Allison, M., Ashcraft, H., Cheng, R., Klawens, S., and Pease, J. (2018). "Integrated project delivery: an action guide for leaders." Charles Pankow Foundation, Integrated Project Delivery Alliance (IPDA), Center for Innovation in the Design and Construction Industry (CIDCI).

Austin, S. A., Baldwin, A. N., and Steele, J. L. (2002). "Improving building design through integrated planning and control." Engineering, Construction and Architectural Management, MCB UP Ltd.

Berg, P. and Reed, D. (2019). "Capability-Building Competition in Construction: Case Study Reinterpretation." Proc. 27 $7^{\text {th }}$ Annual Conference of the International Group for Lean Construction, Dublin, Ireland, 265-274.

Berg, P., Reed, D., and Sriram, S. (2020). "Capability-Building Competition in Design: Case Study." Proc. 28th Annual Conference of the International Group for Lean Construction (IGLC), Berkeley, California, USA, 121-131.

Bertelsen, S. (2003). "Complexity - A New Way of Understanding Construction." 11th Annual Conference of the International Group for Lean Construction, Virginia, USA.

Dekker, S. (2011). Drift into failure: from hunting broken components to understanding complex systems. Ashgate Pub, Farnham ; Burlington, VT.

Duhigg, C. (2012). The power of habit: why we do what we do in life and business. Random House, New York.

Fujimoto, T. (1999). The Evolution of a Manufacturing System at Toyota. Oxford University Press, Inc., New York, New York.

Modig, N., and Åhlström, P. (2012). This is lean: resolving the efficiency paradox. Rheologica Publishing, Stockholm.

Ohno, T. (1988). Toyota production system: beyond large-scale production. Productivity Press, Cambridge, Mass.

Picchi, F. A. (2001). "System View of Lean Construction Application Opportunities." 9th Annual Conference of the International Group for Lean Construction, G. Ballard and D. Chua, eds., Singapore, Singapore.

Seed, W. R. (2014). "Integrated Project Delivery Requires a New Project Manager.” 22nd Annual Conference of the International Group for Lean Construction, B. T. Kalsaas, L. Koskela, and T. A. Saurin, eds., Oslo, Norway, 1447-1459.

Shimokawa, K. and Fujimoto, T. (Eds.). (2009). The Birth of Lean: Conversations with Taiichi Ohno, Eiji Toyoda, and other figures who shaped Toyota management. The Lean Enterprise Institute, Cambridge, Massachusetts.

Sobek, D. K., Liker, J. K., and Ward, A. C. (1998). "Another Look at How Toyota Integrates Product Development.” Harvard Business Review, (July-August 1998 Issue), 12.

Tuholski, S. J., and Tommelein, I. D. (2008). "Design Structure Matrix (DSM) Implementation on a Seismic Retrofit." 16th Annual Conference of the International Group for Lean Construction, P. Tzortzopoulos and M. Kagioglou, eds., Manchester, UK, $471-484$. 